\title{
SENSOR TIMBAL BERBASIS POTENSIOMETRI UNTUK MENDETEKSI KADAR TIMBAL DALAM DARAH
}

\author{
(POTENTIOMETRIC BASED LEAD SENSOR TO DETECT THE LEVELS OF LEAD \\ IN BLOOD)
}

\section{Eka Novitasari, Ayu R. Anggraeni, Muhiroh, Mokhammad W. Dahlan, dan Ani Mulyasuryani}

\author{
Fakultas Ilmu Matematika dan Ilmu Pengetahuan Alam Universitas Brawijaya \\ Jl. Veteran Malang \\ e-mail: mulyasuryani@ub.ac.id
}

\begin{abstract}
Abstrak
Penelitian ini bertujuan menentukan kondisi optimum dalam pengembangan sensor ion timbal dengan melakukan optimasi terhadap beberapa parameter seperti jumlah ionofor dan ketebalan membran. Pada penelitian ini dikembangkan sensor timbal dalam darah berbasis elektroda selektif ion timbal yang dimodifikasi dengan membran kitosan dan garam timbal sulfida $(\mathrm{PbS})$ sebagai bahan aktif (ionofor) yang kemudian dilapiskan pada permukaan SPCE. Konsentrasi bahan aktif $(\mathrm{PbS})$ yang ditambahkan dalam larutan kitosan yaitu $0,5 \%$ sampai $2,5 \%(\mathrm{~b} / \mathrm{v})$. Ketebalan membran yang digunakan yaitu $15 \mu \mathrm{m} ; 25 \mu \mathrm{m} ; 40 \mu \mathrm{m}$; dan $75 \mu \mathrm{m}$. Elektroda diuji pada $\mathrm{pH}$ larutan 2, 3, 4, dan 5 dengan konsentrasi larutan standar $10^{-8} \mathrm{M}$ hingga $10^{-1} \mathrm{M}$. Kinerja optimum elektroda diperoleh pada konsentrasi $\mathrm{PbS} 1,5 \%$ dengan ketebalan membran $15 \mu \mathrm{m}$ dan $\mathrm{pH}$ larutan 4 . Bilangan Nernst yang diperoleh yaitu $24,35 \mathrm{mV} /$ dekade dengan kisaran konsentrasi $0,032 \mathrm{ppm}$ hingga $0,322 \mathrm{ppm}$ dan konsentrasi larutan terkecil yang digunakan yaitu $0,032 \mathrm{ppm}$.
\end{abstract}

Kata kunci: sensor timbal, timbal dalam darah, timbal sulfida

\begin{abstract}
This study was aimed at determining the optimal conditions of lead sensor in the development of ion lead sensor to perform the optimization of several parameters such as the number of ionophores and membrane thickness. In this study, a lead sensor based on lead selective electrode was developed. The electrode was modified by adding lead sulfide in chitosan membran as an active agent (ionophores) and superimposed on the surface of SPCE. The amounts of PbS added in chitosan solution were $0.5 \%, 1 \%, 1.5 \%, 2 \%$, and $2.5 \%(w / v)$. The thickness of membrane used were $15 \mu \mathrm{m}, 20 \mu \mathrm{m}, 45 \mu \mathrm{m}$, and $75 \mu \mathrm{m}$. The sensors were tested in standard solution at concentration $10^{-8} \mathrm{M}$ to $10^{-1} \mathrm{M}$ and at $\mathrm{pH} 2,3,4$, and 5. Lead sensor has optimum performance on PbS 1.5\%, thickness of membrane on $15 \mu \mathrm{m}$ and $\mathrm{pH} 4$. The Nernst factor obtained was $23.45 \mathrm{mV} /$ decade with the solution concentration range $0.032 \mathrm{ppm}$ to $0.322 \mathrm{ppm}$.
\end{abstract}

Keywords: lead in blood,lead sensor, lead sulfide 


\section{PENDAHULUAN}

Timbal merupakan logam berat yang diketahui dapat menjadi racun bagi sistem pernapasan, sistem saraf, serta meracuni darah. Keracunan timbal dapat terjadi karena proses pernapasan, pencernaan (tidak sengaja tertelan) dan terserap oleh kulit. Sumber keracunan timbal dapat berasal dari kendaraan yang menggunakan bahan bakar bertimbal dan juga dari biji logam hasil pertambangan serta berbagai industri (Suherni, 2010). Batas ambang timbal dalam tubuh yaitu 4,8 $\times 10^{-7} \mathrm{M}$ apabila melebihi batas tersebut maka dapat menyebabkan berbagai gangguan kesehatan (Mifbakhuddin, 2007). Oleh karenanya, diperlukan metode cepat dan akurat untuk penentuan kadar ion $\mathrm{Pb}^{2+}$ dalam darah.

Metode analisis secara potensiometri merupakan metode analisis yang mudah dan memiliki akurasi serta ketepatan yang baik. Penggunaan elektroda selektif ion (ESI) sebagai elektroda pada metode potensiometri akan meningkatkan selektivitas dan sensitivitas dari metode tersebut (Primaharinastiti, 2012). Oleh karena itu, dikembangkan suatu sensor berbasis elektroda selektif ion timbal sebagai alat pengujian timbal dalam darah. ESI merupakan elektroda indikator yang dapat dibuat dengan melapiskan suatu garam sukar larut dalam air (ionofor) yang diembankan pada membran untuk mendapatkan elektroda yang selektif (Mulyasuryani, Sabarudin, \& Suryantoro, 2014).

Salah satu elektroda selektif ion timbal yang dikembangkan sebelumnya menggunakan material organik 1-((3-((2-Hydroxynapthalen-1-yl) Methyleneamino)-2,2 Dimethylpropylimino) Methyl)Naphtalen-2-ol sebagai ionofor dan telah diaplikasikan pada sampel air dan tanah. Pada penelitian tersebut dihasilkan bilangan Nernst sebesar 25,79 mV/dekade (Ghaedi et al., 2011). Bilangan Nernst tersebut telah mendekati bilangan Nernst teoritis yaitu 29,6 $\mathrm{mV}$ /dekade namun masih dapat ditingkatkan dengan cara memodifikasi elektroda. Oleh karena itu pada penelitian ini dilakukan modifikasi elektroda dengan menggunakan ionofor berupa material anorganik yaitu timbal sulfida $(\mathrm{PbS})$.

Elektroda selektif ion timbal yang dikembangkan dalam penelitian ini didasarkan pada reaksi kesetimbangan pengendapan (Mulyasuryani, dkk., 2014). Hal ini karena yang digunakan sebagai bahan aktif adalah PbS. Pada saat pengukuran akan terjadi reaksi kesetimbangan (Oxtoby, 2001):

$$
\mathrm{PbS}_{(j)}+\mathrm{H}_{2} \mathrm{O}_{(l)} \rightleftharpoons \mathrm{Pb}_{(a q)}^{2+}+\mathrm{OH}_{(a q)}^{-}+\mathrm{HS}_{(a q)}^{-} \mathrm{Ksp}=3 \times 10^{-28}(1)
$$
dengan adanya pergesaran kesetimbangan yang diakibatkan oleh perubahan jumlah ion $\mathrm{Pb}^{2+}$ dalam larutan analit maka akan dihasil-kan perbedaan potensial membran. Perhitungan potensial sel pada elektroda dituliskan sebagai berikut (Wang, 2006): 


$$
\begin{aligned}
& \text { Esel }=\text { Eind }- \text { Ereff }+E l j \\
& \text { Eind }=k-0,029 \log \left[P b^{2+}\right]
\end{aligned}
$$

Dengan menggunakan elektroda $\mathrm{Ag} /$ $\mathrm{AgCl}$ sebagai elektroda pembanding, maka:

$$
\begin{aligned}
& \text { Esel }=k-0,0296 \log \left[\mathrm{Pb}^{2+}\right]-0,222 \\
& \text { Esel }=K-0,0296 \log \left[\mathrm{Pb}^{2+}\right]
\end{aligned}
$$

Sejumlah penelitian yang telah dilakukan menunjukkan bahwa kinerja ESI dipengaruhi oleh konsentrasi ionofor, ketebalan membran dan $\mathrm{pH}$ larutan. Konsentrasi ionofor dan ketebalan membran mempengaruhi jumlah kesetimbangan dan kerapatan ion dalam membran, sehingga berakibatpada nilai potensial selyang terukur. Sensitivitas dari elektroda dipengaruhi pula oleh $\mathrm{pH}$ larutan, dimana $\mathrm{pH}$ larutan (dalam hal ini aktivitas ion $\mathrm{H}^{+}$) berpengaruh pada harga Nernst dari elektroda (Primaharinastiti, 2012; Sari, 2010; Rosemiyani, 2013). Oleh karena itu, pada penelitian ini dilakukan optimasi pembuatan elektroda dengan mengatur jumlah $\mathrm{PbS}(\%)$ yang diembankan pada membran dan ketebalan membran serta pengaturan $\mathrm{pH}$ pengukuran. Sensor yang dihasilkan kemudian diaplikasikan pada sampel darah.

\section{METODE PENELITIAN}

Alat yang digunakan dalam penelitian ini adalah Multimeter Digital Sanwa CD800a, Adapter Quasense, SPCE (Screen
Printed Carbon Electrode) Quasense, peralatan gelas, AAS Shimadzu AA-6200, pH meter Senz TI-13MO597. Bahan yang digunakan adalah $\mathrm{PbS}$ yang dibuat dari $\mathrm{Pb}\left(\mathrm{NO}_{3}\right)_{2}$ dan $\mathrm{H}_{2} \mathrm{~S}$, kitosan, asam asetat $2 \%$, akuademineral, $\mathrm{HNO}_{3}$ pekat, $\mathrm{HCl} 1: 1, \mathrm{Na}_{2} \mathrm{~S}$, sampel darah, glutaraldehid $0,01 \%$.

Prosedur kerja dalam penelitian ini dijelaskan sebagai berikut. Membran dibuat dari 0,1 gram kitosan dan ditambahkan 10 $\mathrm{mL}$ asam asetat $2 \%$ kemudian dihomogenkan selama 24 jam. Larutan kitosan diambil sebanyak $1 \mathrm{~mL}$ dan ditambahkan ionofor pada masing-masing larutan sebanyak 0,005 $\operatorname{gram}(0,5 \% \mathrm{~b} / \mathrm{v}) ; 0,010 \operatorname{gram}(1 \% \mathrm{~b} / \mathrm{v}) ; 0,015$ $\operatorname{gram}(1,5 \% \mathrm{~b} / \mathrm{v}) ; 0,020 \operatorname{gram}(2 \% \mathrm{~b} / \mathrm{v})$ dan 0,025 gram $(2,5 \% \mathrm{~b} / \mathrm{v})$. Campuran kemudian ditambahkan glutaraldehid 0,01\% sebanyak $25 \mu \mathrm{L}$ dan diaduk kembali selama 24 jam. Campuran yang diperoleh diambil sebanyak $10 \mu \mathrm{L}$ dan dilapiskan pada SPCE, kemudian dikeringkan dalam oven pada temperatur $50^{\circ} \mathrm{C}$ selama satu jam. Penentuan ketebalan membran optimum dilakukan dengan melapiskan kitosan pada permukaan SPCE sehingga diperoleh ketebalan membran 15 $\mu \mathrm{m} ; 25 \mu \mathrm{m} ; 40 \mu \mathrm{m}$ dan $75 \mu \mathrm{m}$.

Elektroda dengan hasil optimum diuji pada $\mathrm{pH}$ larutan 2; 3; 4 dan 5 dengan konsentrasi larutan standar $\mathrm{Pb}\left(\mathrm{NO}_{3}\right)_{2} \quad 10^{-8}$ $\mathrm{M} ; 10^{-7} \mathrm{M} ; 10^{-6} \mathrm{M} ; 10^{-5} \mathrm{M} ; 10^{-4} \mathrm{M} ; 10^{-3} \mathrm{M}$; $10^{-2} \mathrm{M}$ dan $10^{-1} \mathrm{M}$. Pengaturan $\mathrm{pH}$ dilakukan dengan menambahkan larutan $\mathrm{HNO}_{3}$. 
Jurnal Penelitian Saintek, Vol. 21, Nomor 1, April 2016

Sampel darah diukur volumenya dan didekstruksi dengan $\mathrm{HNO}_{3} \quad 65 \%$, pada temperatur $70-80^{\circ} \mathrm{C}$ hingga terbentuk larutan kuning jernih. Hasil dekstruksi diencerkan dalam labu ukur $5 \mathrm{~mL}$, dengan larutan $\mathrm{HNO}_{3}$ pH 4. Penentuan kadar sampel dilakukan dengan adisi standar.

\section{HASIL DAN PEMBAHASAN}

\section{Penentuan Konsentrasi Ionofor Optimum}

Tabel 1

Kinerja Sensor pada Berbagai Konsentrasi Ionofor

\begin{tabular}{ccc}
\hline $\begin{array}{c}\text { Konsentrasi } \\
\text { ionofor, \% } \\
(\mathrm{b} / \mathrm{v})\end{array}$ & $\begin{array}{c}\text { Bilangan } \\
\text { Nernst, } \mathrm{mV} / \\
\text { dekade }\end{array}$ & $\begin{array}{c}\text { Kisaran } \\
\text { Konsentrasi, } \\
\mathrm{M}\end{array}$ \\
\hline 0,5 & - & - \\
1,0 & 63,95 & $10^{-7}-5 \cdot 10^{-7}$ \\
1,5 & 19,88 & $10^{-6}-5 \cdot 10^{-6}$ \\
2,0 & - & - \\
2,5 & 14,03 & $10^{-7}-5 \cdot 10^{-6}$ \\
\hline
\end{tabular}

Konsentrasi ionofor akan berpengaruh terhadap selektivitas elektroda (Ceresa, 2001). Bühlman dan Chen (2012) menyatakan bahwa peningkatan konsentrasi ionofor akan meningkatkan selektivitas dari elektroda. Peningkatan selektivitas hanya terjadi hingga konsentrasi ionofor tertentu. Pada konsentrasi yang lebih tinggi dari harga optimum akan menyebabkan penurunan selektivitas elektroda. Fenomena tersebut juga ditemukan dalam penelitian ini.

Pada konsentrasi $0,5 \%$ bilangan Nernst tidak muncul karena jumlah
$\mathrm{PbS}$ yang terlalu sedikit akan terganggu kesetimbangannya oleh anion $\left[\mathrm{NO}_{3}^{-}\right]$yang jumlahnya lebih banyak yaitu $2 \times 10^{-8} \mathrm{M}$ hingga $2 \times 10^{-1} \mathrm{M}$. Konsentrasi ionofor $1 \%$ menghasilkan bilangan Nernst terlalu jauh dari harga Nernst teoritis yaitu 29,6 mV/ dekade yang kemungkinan disebabkan oleh adanya gangguan dari kation lain seperti $\mathrm{H}^{+}$. Gangguan dari ion tersebut dapat diminimalkan dengan pengaturan $\mathrm{pH}$ larutan uji. Konsentrasi ionofor 1,5\% merupakan konsentrasi ionofor yang menghasilkan bilangan Nernst mendekati teoritis. Pada konsentrasi ini ionofor dapat berkesetimbangan dengan baik dan kemungkinan memiliki homogenitas yang baik. Pada konsentrasi yang lebih tinggi homogenitas ionofor dalam membran menurun. Penurunan homogenitas dapat menimbulkan ketidakseragaman pencapaian kesetimbangan reaksi pada permukaan membran, sehingga dapat menurunkan kepekaan.

\section{Penentuan Ketebalan Membran Optimum}

Tabel 2

Kinerja Sensor Timbal pada Berbagai

Ketebalan Membran

\begin{tabular}{ccc}
\hline $\begin{array}{c}\text { Ketebalan } \\
\text { Membran, } \\
\mu \mathrm{m}\end{array}$ & $\begin{array}{c}\text { Bilangan } \\
\text { Nernst, mV/ } \\
\text { dekade }\end{array}$ & $\begin{array}{c}\text { Kisaran } \\
\text { Konsentrasi, } \\
\mathrm{M}\end{array}$ \\
\hline 15 & 12,85 & $10^{-5}-10^{-1}$ \\
25 & 9,30 & $10^{-2}-10^{-1}$ \\
40 & 9,67 & $10^{-7}-10^{-5}$ \\
75 & - & - \\
\hline
\end{tabular}


Aini (2016) menjelaskan peningkatan ketebalan membran berpengaruh pada kepekaan sensor. Semakin tebal membran yang dilapiskan pada elektroda maka kepekaan sensor akan menurun. Berdasarkan Tabel 2 dapat diketahui bahwa ketebalan membran berpengaruh terhadap kinerja sensor. Semakin tebal membran maka kesetimbangan yang terjadi di luar membran dan di dalam membran akan lebih lambat terjadi. Apabila kesetimbangan berlangsung lambat maka akan berpengaruh terhadap harga beda potensial sehingga kepekaan menurun. Dari data tersebut diketehui bahwa ketebalan membran optimum yaitu $15 \mu \mathrm{m}$. Pada ketebalan tersebut kesetimbangan dapat berlangsung dengan cepat sehingga dihasilkan bilangan Nernst yang cukup baik sedangkan pada ketebalan $25 \mu \mathrm{m}$ dan $40 \mu \mathrm{m}$ terjadi penurunan kepekaan yang ditandai dengan menurunnya bilangan Nernst.

\section{Penentuan pH Pengukuran}

Tabel 3

Kinerja Sensor Timbal pada Berbagai pH Pengukuran

\begin{tabular}{ccc}
\hline pH Larutan & $\begin{array}{c}\text { Bilangan } \\
\text { Nernst, mV/ } \\
\text { dekade }\end{array}$ & $\begin{array}{c}\text { Kisaran } \\
\text { Konsentrasi, } \\
\mathrm{M}\end{array}$ \\
\hline 2 & 15,01 & $10^{-1}-10^{-5}$ \\
3 & 9,40 & $10^{-1}-10^{-3}$ \\
4 & 18,7 & $10^{-5}-10^{-7}$ \\
5 & 10,58 & $10^{-1}-10^{-3}$ \\
\hline
\end{tabular}

Berdasarkan data tersebut dapat diketahui bahwa $\mathrm{pH}$ larutan saat pengukuran berpengaruh terhadap kinerja sensor. Pada $\mathrm{pH}$ rendah jumlah ion $\mathrm{H}^{+}$dalam larutan akan lebih banyak dibandingkan dengan jumlah ion $\mathrm{Pb}^{2+}$ sehingga kesetimbangan ion timbal akan terganggu (Primaharinastiti, 2012). Pengaruh $\mathrm{pH}$ juga dapat dilihat dari reaksi kesetimbangan berikut (Oxtoby, 2001).

$$
\mathrm{PbS}_{(s)}+\mathrm{H}_{2} \mathrm{O}_{(l)} \rightleftharpoons \mathrm{Pb}_{(a q)}^{2+}+\mathrm{OH}_{(a q)}^{-}+\mathrm{HS}_{(a q)}^{-}
$$

Dari reaksi kesetimbangan tersebut dapat diketahui bahwa pada $\mathrm{pH}$ tinggi maka kesetimbangan akan bergeser ke $\mathrm{PbS}$ (kiri) sehingga jumlah ion timbal akan berkurang dan akan berpengaruh pada kesetimbangan di dalam membran. $\mathrm{pH}$ optimum pada pengujian sensor yaitu pada $\mathrm{pH}$ 4. Pada tahap penelitian selanjutnya $\mathrm{pH}$ larutan akan diatur hingga $\mathrm{pH} 4$ sehingga akan diperoleh hasil yang optimum.

\section{Karakterisasi Elektroda}

Tabel 4

Karakterisasi Elektroda

\begin{tabular}{ll}
\hline \multicolumn{1}{c}{ Karakterisasi } & \multicolumn{1}{c}{ Nlektroda } \\
\hline $\begin{array}{l}\text { Bilangan Nernst } \\
\text { Waktu respon }\end{array}$ & $\begin{array}{l}\text { 24,35 } \pm 5,07 \mathrm{mV} \\
80 \text { detik }\end{array}$ \\
$\begin{array}{l}\text { Kisaran } \\
\text { konsentrasi }\end{array}$ & $0,322 \mathrm{ppm}-0,032 \mathrm{ppm}$ \\
$\begin{array}{l}\text { Konsentrasi } \\
\text { larutan terkecil } \\
\text { yang digunakan }\end{array}$ & $0,032 \mathrm{ppm}$ \\
\hline
\end{tabular}




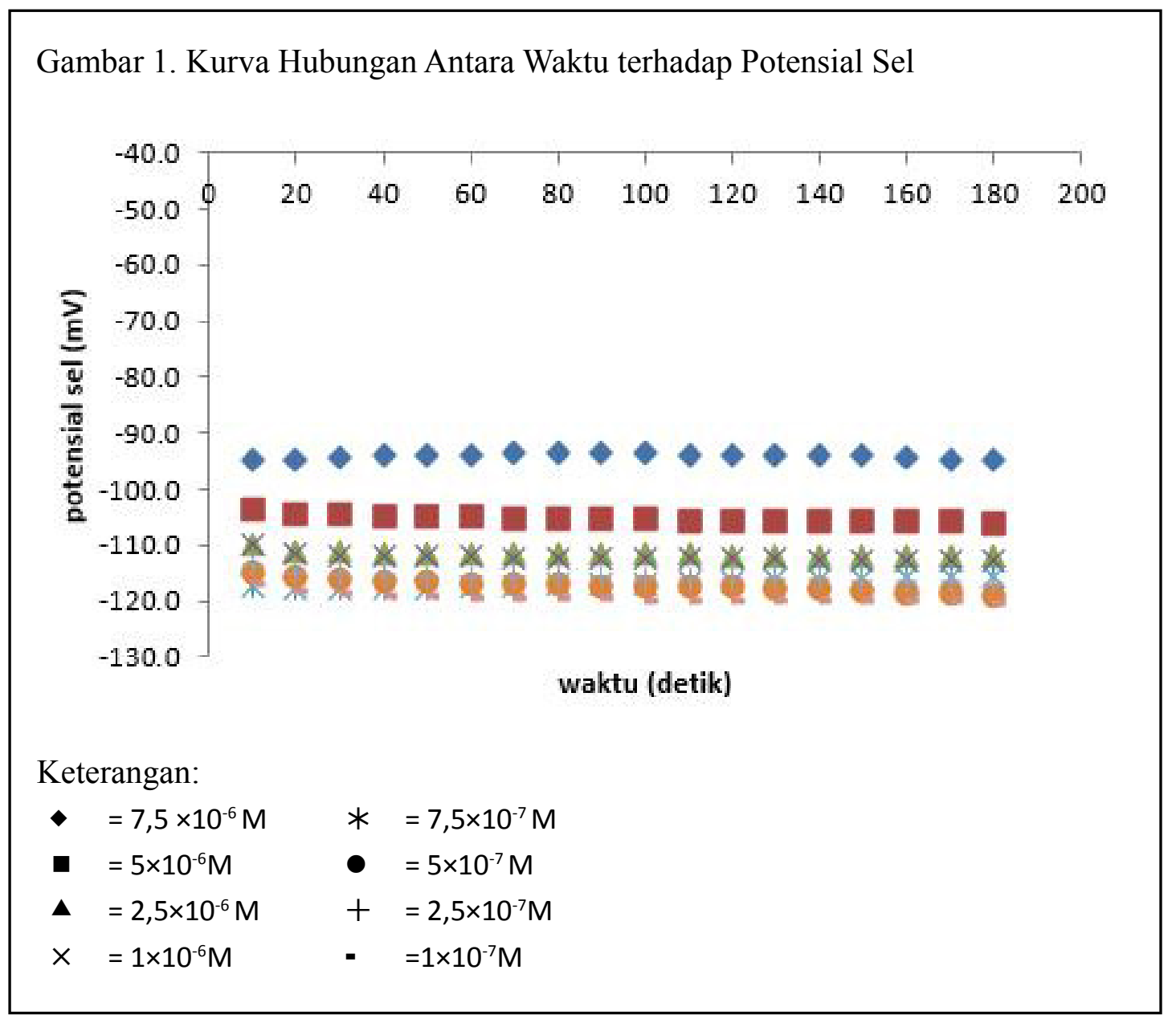

Karakterisasi sensor dilakukan pada kondisi optimum yaitu konsentrasi ionofor 1,5\%, ketebalan membran $15 \mu \mathrm{m}$ dan $\mathrm{pH}$ larutan 4. Dari hasil karakerisasi diperoleh waktu respon, bilangan Nernst, dan kisaran konsentrasi. Waktu respon adalah waktu yang dibutuhkan terjadi kesetimbangan antara ion timbal dalam larutan analit dengan ionofor. Waktu respon dipengaruhi oleh konsentrasi larutan, konsentrasi larutan yang lebih besar memberikan waktu respon yang lebih kecil, karena kesetimbangan terjadi lebih cepat. waktu respon sensor yang dihasilkan yaitu 80 detik. Kisaran konsentrasi yang dapat terukur yaitu 0,032 ppm- 0,322 ppm $\left(1 \times 10^{-7} \mathrm{M}\right.$ $\left.-1 \times 10^{-6} \mathrm{M}\right)$. Bilangan Nernst yang dihasilkan yaitu 24,35 mV/dekade, harga tersebut mendekati bilangan Nernst teoritis untuk ion divalen yaitu 29,6 $\mathrm{mV}$.

\section{Penentuan Kadar Ion Timbal dalam Darah \\ Tabel 5 menyajikan analisis sampel darah dengan sensor $\mathrm{Pb}^{2+}$.}


Tabel 5

\begin{tabular}{ccc}
\multicolumn{2}{c}{ Analisis Sampel Darah dengan Sensor $\mathrm{Pb}^{2+}$} \\
\cline { 2 - 3 } Sampel & \multicolumn{2}{c}{ Konsentrasi (ppm) } \\
\cline { 2 - 3 } & \multirow{2}{*}{ Sensor $\mathrm{Pb}^{2+}$} & Instrumentasi \\
& AAS \\
\hline 1 & $23,22 \pm 0,05$ & 0,18 \\
2 & $51,35 \pm 1,51$ & 4,69 \\
\hline
\end{tabular}

Analisis sampel darah dengan sensor timbal dilakukan dengan metode adisi standar. Berdasarkan data validasi dengan instrumentasi AAS dapat diketahui bahwa hasil analisis menggunakan sensor $\mathrm{Pb}^{2+}$ berbeda secara nyata dengan hasil analisis menggunakan instrumentasi AAS. Hal ini kemungkinan dikarenakan adanya gangguan kation lain yang terdapat dalam darah seperti ion kalsium dan ion magnesium yang juga ikut terdeteksi oleh sensor ion timbal. Walaupun demikian sensor timbal yang dibuat memiliki standar deviasi relatif kecil pada pengukuran sehingga dapat dikatakan bahwa sensor $\mathrm{Pb}^{2+}$ memiliki ketelitian cukup baik.

\section{SIMPULAN}

Berdasarkan penelitian yang dilakukan dapat disimpulkan bahwa sensor ion timbal dapat dibuat berdasarkan konsep elektroda selektif ion dengan melapiskan ionofor yang telah diembankan pada membran kitosan dan dilapiskan pada permukaan SPCE (Screen Printed Carbon Electrode). Sensor ion timbal memiliki kinerja optimum pada konsentrasi ionofor 1,5\%, ketebalan membran $15 \mu \mathrm{m}$ dan $\mathrm{pH}$ pengukuran 4 . Bilangan Nernst yang diperoleh yaitu 24,35 $\mathrm{mV} /$ dekade dengan kisaran konsentrasi 0,032 ppm hingga 0,322 ppm dan konsentrasi larutan terkecil yang digunakan yaitu $0,032 \mathrm{ppm}$. Penerapan sensor timbal pada sampel darah masih belum menunjukkan kinerja yang optimum sehingga masih perlu dilakukan pengembangan lebih lanjut untuk mendapatkan sensor yang lebih selektif.

\section{DAFTAR PUSTAKA}

Aini, Z. (2016). Pengaruh ketebalan membran kitosan terhadap kinerja sensor fenol potensiometri berbasis Screen Printed Carbon Electrode (SPCE) (Skripsi). Fakultas Matematika dan Ilmu Pengetahuan Alam Universitas Brawijaya, Malang.

Bühlman, P., \& Chen, L. D. (2012). Supramolecular chemistry: From molecules to nanomaterials. USA: John Wiley and Sons.

Ceresa, A. (2001). Ion-selective polymeric membrane electrodes for potentiometrie trace level measurements (Doctoral Dissertation). Swiss Federal Institute of Technology Zurich, Swiss.

Ghaedi, M., Montazerozohori, M., Andikaey, Z., Shokrollahi, A., Khodadoust, S., Behfar, M., \& Sharifi, S. (2011). Fabrication of $\mathrm{Pb} 2+$ Ion Selective Electrode Based on 1-((3-)(2-Hydroxynaphthalen1 - y l) Methylenea mino ) - 2, 2 Dimethylpropylimino)Methyl) Naphthalen-2-ol as New Neutral 
Ionophore. International Journal of Electrochemical Science, 6, pp. 41274140.

Mifbakhuddin. (2007). Hubungan kadar Pb dalam darah dengan profil darah pada petugas operator stasiun pengisian bahan bakar umum di Daerah Kota Semarang Timur. Jurnal Kesehatan Masyarakat Indonesia, 4(2), 51-60.

Mulyasuryani, A., Sabarudin, A., \& Suryantoro, A. (2014). Pengaruh konsentrasi cetyltrimethylammonium benzoat dan $\mathrm{pH}$ larutan terhadap kinerja elektroda selektif ion benzoat berbasis screen printed carbon electrode. Kimia Student Journal, 2(1), 313-319.

Oxtoby, D. W. (2001). Prinsip-prinsip dasar kimia modern. Jakarta: Erlangga.

Primaharinastiti, R. (2012). Pembuatan dan karakterisasi elektrode selektif ion
(ESI) salbutamol berbasis membran tipe kawat terlapis. Berkala Ilmiah Kimia Farmasi, 1(1).

Rosemiyani, I. (2013). Pengaruh pH dan ion asing terhadap kinerja elektroda selektif ion (ESI) timbal (II) tipe kawat terlapis unutk menentukan kandungan timbal dalam Kosmetik (Skripsi). Universitas Brawijaya, Malang.

Sari, D. P. (2010). Pengaruh konsentrasi $\mathrm{Ba}\left(\mathrm{IO}_{3}\right)_{2}$ dan ketebalan membran kitosan terhadap kinerja elektroda selektif ion (ESI) iodat (Skripsi). Universitas Brawijaya, Malang.

Suherni. (2010). Keracunan timbal di Indonesia (Thesis). Macquarie University, Sydney, Australia.

Wang, J. (2006). Analytical electrochemistry ( $3^{\text {rd }}$ ed.). Hoboken: Wiley-VCH. 